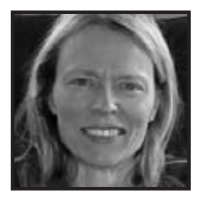

\title{
Through the Lens of One Day Last December: A Poetics of Narrative Teaching
}

\author{
Cynthia M. Morawski, University of Ottawa
}

\section{ABSTRACT}

Thoughtful teaching requires the mapping of one's own life, a land marked with features of recalled sites. In the studio of my own classroom practice, working material resides in the poetic groundwork of after-school treks along contours of a New England shoreline. A black stone library. A harbor sound. The placement of a dogwood by a marshy pond. Through the lens of one day last December, read on...

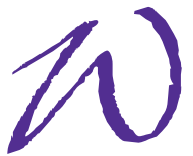

hile composing her own story of growing up, Annie Dillard (1987) came to realize, "When everything else has gone from my brain-what will be left, I believe, is topology: the dreaming memory of land as it lay this way and that...the city poured rolling down the mountain valley like slag..." (p. 3). Within the terrain of a lived story, the curriculum of the present emerges from selected texts of recollected pasts-narrations in returning futures. Thoughtful teaching requires the mapping of one's own life, a land marked with features of recalled sites. In the studio of my own classroom practice, working material resides in the poetic groundwork of after-school treks along contours of a New England shoreline. Treads of white-walled radials wear a path through crushed asphalt and marsh. Stopping along the way, I place chosen moments in a wire basket attached to the chrome of rusting handlebars. Back on my turquoise bike, I ride off, charting chosen scenes of life in teaching. Read on... 


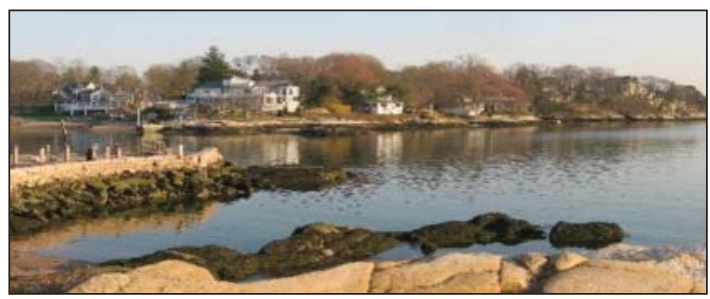

Through the lens of one day last December

The aperture of memory takes photographs without a flash, A succession of scenes

Spread along a coastal breakwater.

From a distance

Tankers watch the rocky shoreline,

Where shutters of July homes catch snowflakes

Drifting into currents of offshore ferries.

Standing near a boat house window

Painted metal pail in hand,

A sea glass collector sifts through the presence of low tide

Past images catalogued in current color.

At the side of a beach wall landing

Stone steps bring her to limestone benches,

Time pieces fixed in fragments of inner conversations

Slipping by like sailboats unnoticed.

Across salt stained slats of late summer tables, She arranges remembered moments

Culled from curricula

Of never forgotten time.

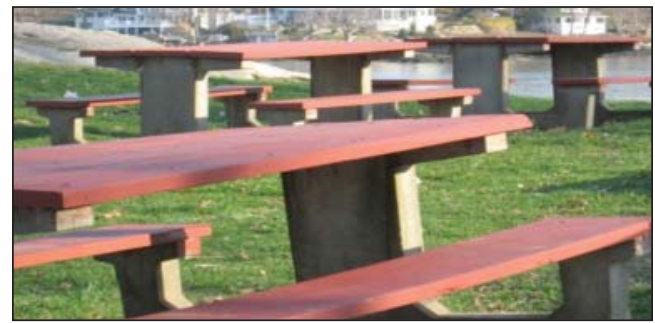


Next to a cedar street hedge

A library stands in memorial of black stone marble,

Rooms of casement windows fill walls with fables long ago

Biographies of familiar strangers.

Footing a narrow stairwell

Alcoves of shelves store geographies next to world globes.

Stacked newspapers hold readers' attention

As lights flicker in between iron laths of an upper floor.

Stacked on a check-out counter overlooking oak stained chairs

Books take turns being stamped by fines of overdue dates,

Front foyers opening up into metal carvings

Lean against the remembered meanings of another day.

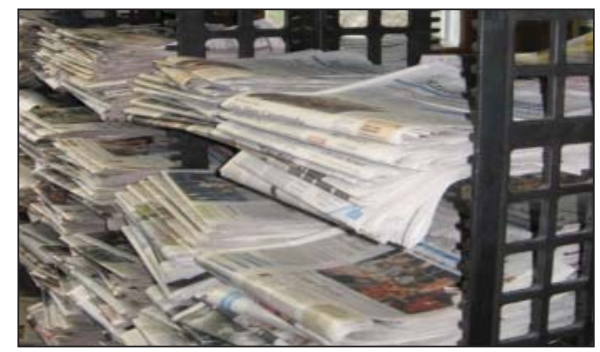

On the branches of a feral apple tree

Hammered pieces of plywood act as the fort's sentry,

To the right, tall grasses border an eastern hill

Pushing sleds onto icy mats of a reedy field.

Undetected from above

An underground hideaway carves into earth with borrowed shovels,

Ladders lashed together with found string and sticks

Permit entry into secret quarters. 


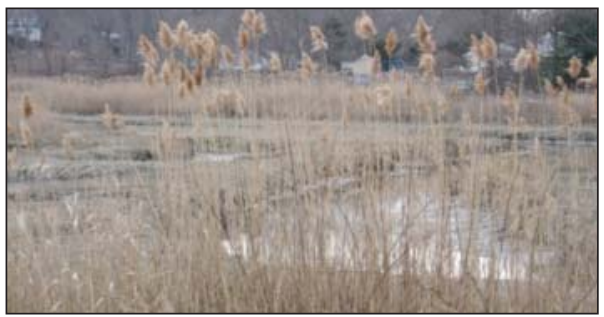

Across the mowed lawn

The lilting call of a red-winged blackbird

Perches on pulleys attached to a clothesline railing,

A metal milk box awaits delivery unopened.

Looking back through sketch pad pages

Forsythias color lilacs with the pastels of a painter's box, Willows weep next to dogwood trees on distant hills Backing onto a deserted barn filled with paper.

Raked into uneven piles in front of a detached garage Mosaic tiles leave red and orange maples, Hours later, an unsuspecting swipe of a double-pawed calico Slinks into the shadows of a public motorcade.

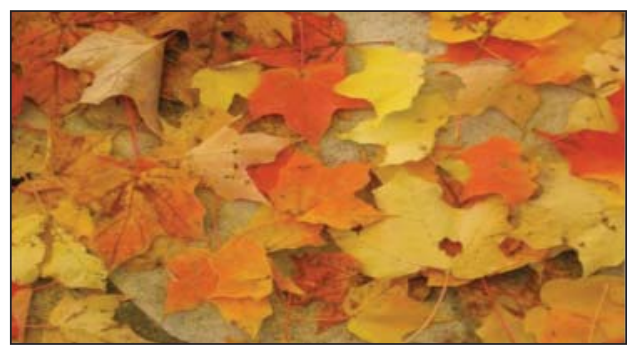

After replacing one more moment

Into her metal pail,

The sea glass collector

Packs up and turns towards another poem. 
Without warning an unexpected moment of memory

Tilts sun umbrellas staked next to a harbour road,

Pinwheels circle the front entrance of a candy store

Shaded by the weather of striped awnings.

Installed next to a sunken barge

Whirligigs set down in sand bar waters,

Moving out of tune

Timed to the dials of transistor radios.

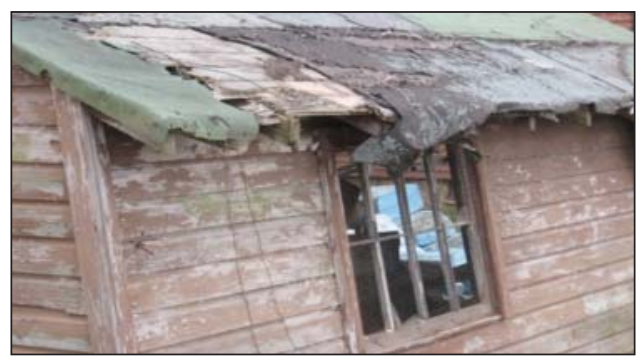

Placed on the striped towel of an early evening swim

A beach ball slips away from the pull of incoming tide,

Footprints fade into the cadence of waves

Leaving latticework of salt and seaweed.

While winkle shells disappear for the night

Fireflies blink the last call of a lemonade stand,

Porch lights pursue pebbled paths ending in screen doors

Opening and closing against the frames of another day.

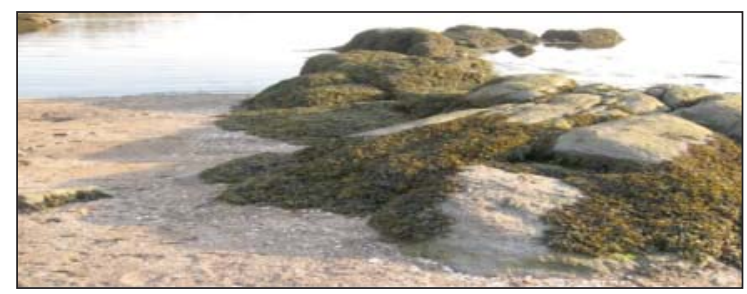


When Georgia O'Keefe taught, she wanted to show her students a way of seeing. She told them that there was meaning in "...the way one addressed a letter, combed one's hair, or placed a window in a house" (Lisle, 1986, p. 71). In the lines of poetic observation, past experiences act as reference maps of topographies in future presents. Working material of memory makes meaning in the teaching of curricular plans. Icy mats of a reedy field become fables of an apple tree. Rooms of casement windows stage puppets beside a chalkboard wall. Sketchpads draw words in colors, shapes, and other ways to know. Adler (1958) observed that we are both the picture and the artist. I say the poem and the poet, moving within selected moments of perceptual time. A black stone library. A harbor sound. The placement of a dogwood by a marshy pond...

\section{References}

Adler, A. (1958). The practice and theory of individual psychology. Patterson, NJ: Littlefield, Adams.

Dillard, A. (1987). An American childhood. New York: Harper Perennial.
Lisle, L. (1986). Portrait of an artist: A biography of Georgia O'Keefe. Albuquerque: University of New Mexico Press.

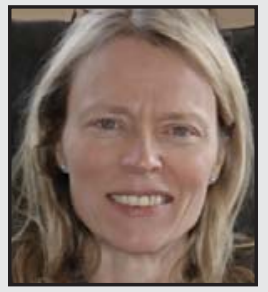

Cynthia Morawski received her doctorate from Columbia University Teachers College. She is currently an associate professor in the Faculty of Education, University of Ottawa, where she teaches integrated language/arts, literacy, disabilities studies, and literature, and researches literacy learning; bibliotherapy; women's lives; and arts-based learning, including poetics of memory work in teaching narratives and learning differences. 